\title{
Corrosion Evolution of Steel Reinforced Concrete Under Simulated Tidal and Immersion Zones of Marine Environment
}

\author{
Jie Wei ${ }^{1} \cdot$ Chang-Gang Wang ${ }^{1} \cdot$ Xin Wei $^{1} \cdot$ Xin Mu$^{1} \cdot$ Xiao-Yan He ${ }^{1} \cdot$ Jun-Hua Dong ${ }^{1} \cdot$ Wei Ke $^{1}$
}

Received: 27 September 2018 / Revised: 8 November 2018 / Published online: 1 January 2019

(c) The Chinese Society for Metals (CSM) and Springer-Verlag GmbH Germany, part of Springer Nature 2019

\begin{abstract}
The corrosion evolution processes of steel reinforced concrete under simulated tidal and immersion zones of marine environment were investigated by using electrochemical measurements and corrosion morphology observations. The results indicate that the corrosion of rebar in concrete under both environments experiences the deterioration from passivation to pitting corrosion and then to general corrosion. Specially, the pitting plays the major role only in the early stage of corrosion, and the general corrosion replaces the dominate role of pitting during the long-term corrosion. In addition, both the pitting depth on local surface and the rust thickness on the overall surface of rebar in the tidal condition are larger than those in immersion condition, which is attributed to the faster corrosion rate in tidal zone caused by the concentrated chloride ions and sufficient oxygen supply.
\end{abstract}

Keywords Marine environment $\cdot$ Reinforced concrete $\cdot$ Corrosion evolution $\cdot$ Pitting $\cdot$ General corrosion

\section{Introduction}

In marine environment, chloride-induced corrosion of steel reinforced concrete is the main cause for the durability degradation of reinforced concrete $(\mathrm{RC})$ structures [1-3]. This corrosion leads to many problems for RC structures, such as reducing the bearing capacity and service safety and increasing the maintenance and renovation cost $[4,5]$. Therefore, the corrosion degradation of RC structures in marine environment attracts widespread attention.

Corrosion evolution of rebar in concrete is the long-term and complex chemical and electrochemical processes that occur at the interface between rebar and its surrounding concrete environment. Usually, in the high alkaline concrete environment $(\mathrm{pH}=12.6-13.5)$ free of corrosive ions, a layer of compact passive film which can protect the rebar against corrosion formed on rebar surface [6]. However, as this passive film is only dozens of angstroms, it is easy to be

Available online at http://link.springer.com/journal/40195

Jun-Hua Dong

jhdong@imr.ac.cn

1 Environmental Corrosion Center, Institute of Metal Research, Chinese Academy of Sciences, Shenyang 110016, China destroyed by $\mathrm{Cl}^{-}$when its concentration reaches or exceeds its threshold value [7, 8]. Under this condition, the potential difference exists between the exposed rebar matrix (acting as anode) and the intact passive film (acting as cathode), which will cause the galvanic corrosion. Moreover, with the propagation of corrosion, the corrosion products would gradually produce and accumulate at the interface of rebar and concrete, and it can cause the volume expansion of 4-6 times more than that of the corroded steel. This will lead to the serious consequences of cracking and even spalling of concrete layer [9-12]. Therefore, the initiation and propagation processes of rebar corrosion are associated with the deterioration rate of RC structures [13]. By understanding the corrosion evolution processes and the affecting factors on corrosion rate, the durability of RC structures can be improved by controlling the corrosion of rebar [14].

The corrosion evolution of RC structures in marine environment is significantly influenced by the specific service environment. According to a large number of engineering surveys, it is found that the corrosion problem of RC structures in tidal zone is the most severe [15-17]. Otieno et al. found that pitting corrosion is significant in tidal zone to cause the corrosion cracking of RC structures [18]. In the immersion zone, it was also found that the corrosion of rebar normally appears pitting pattern in chloride-contaminated $\mathrm{RC}$ structures. The non-uniform distribution of rust between 
steel and concrete interface is mainly caused by galvanic corrosion between the active and passive rebar surfaces [19]. Up to now, the corrosion evolution process of reinforced concrete in tidal zone and immersion zone and the difference between the two are still not fully understood. Therefore, it is necessary to study the corrosion degradation processes and mechanism of rebar in RC structures in different zones of marine environment.

Normally, the test in real sea site and the environmental simulated test in laboratory are two main experimental methods used for studying the corrosion of RC structures in marine environment [20-24]. The test in real sea site can reflect the comprehensive effect of the complex environmental factors, and the results obtained are in accordance with the actual service process [25, 26]. However, the test in real sea site is a destructive method and usually takes from a few years to a few decades. Besides, it is of great difficulties to study the corrosion evolution processes and mechanism, such as the change of corrosion rate, the electrode reaction kinetics and the rust composition changes. As comparison, the environmental simulated test in laboratory can shorten the test period through the accelerated corrosion experiments and clarify the corrosion evolution by nondestructive method of electrochemical monitoring [27, 28]. Therefore, it is more appropriate for studying the corrosion evolution mechanism.

In this study, the corrosive environment of tidal zone and immersion zone was simulated in laboratory, and the corrosion evolution processes and mechanism of rebar in concrete in these two zones were studied by electrochemical measurements and corrosion morphology observations.

\section{Experimental}

\subsection{Material and Procedures}

\subsubsection{Rebar Samples Preparation}

The tested steel used was a commercial 20SiMn hot-rolled rebar with the elemental compositions (wt\%) of 0.17-0.25 C, 1.20-1.60 Mn, 0.40-0.80 Si, 0.0500 P, 0.050 S and Fe (balance). The rebar samples were machined into cylinders $(\Phi 10 \mathrm{~mm} \times 60 \mathrm{~mm})$, and the surfaces were polished using 2000-grit $\mathrm{SiC}$ paper.

\subsubsection{Concrete Sample Preparation}

RC cylindrical samples $(80 \mathrm{~mm}$ in diameter and $80 \mathrm{~mm}$ in height) were cast according to standard experimental procedures using ordinary Portland cement 42.5 (with a water/ cement ratio of 0.5 and cement/sand ratio of 1/3) [29]. The schematic diagram of the electrode system is shown in Fig. 1, and all the length units are in millimeter [30]. A three-electrode cell was used in this experiment. The working electrode (WE) was the machined rebar sample. Both ends of the rebar were coated with dense epoxy, leaving an exposed cylindrical surface with a length of $40 \mathrm{~mm}$. The rebar was positioned at the center of the concrete sample with a cover thickness of $35 \mathrm{~mm}$. The reference electrode (RE) was $\mathrm{Cu} / \mathrm{CuSO}_{4}$ electrode which was positioned in the concrete $5 \mathrm{~mm}$ from the WE surface to reduce the IR drop between WE and RE. In order to distribute the electrical signal uniformly, a 60-mm-height annular graphite electrode was used as the counter electrode (CE), which was positioned in the concrete with the cover thickness of $11 \mathrm{~mm}$. The concrete samples were demoulded at one day after casting, and then, they were cured in a standard curing chamber at $20 \pm 1{ }^{\circ} \mathrm{C}$ and $\geq 95 \% \mathrm{RH}$ for 28 days. In order to avoid the non-uniform penetration of solution, both ends of the concrete samples were coated with epoxy resin leaving 40-mmheight profile exposed.
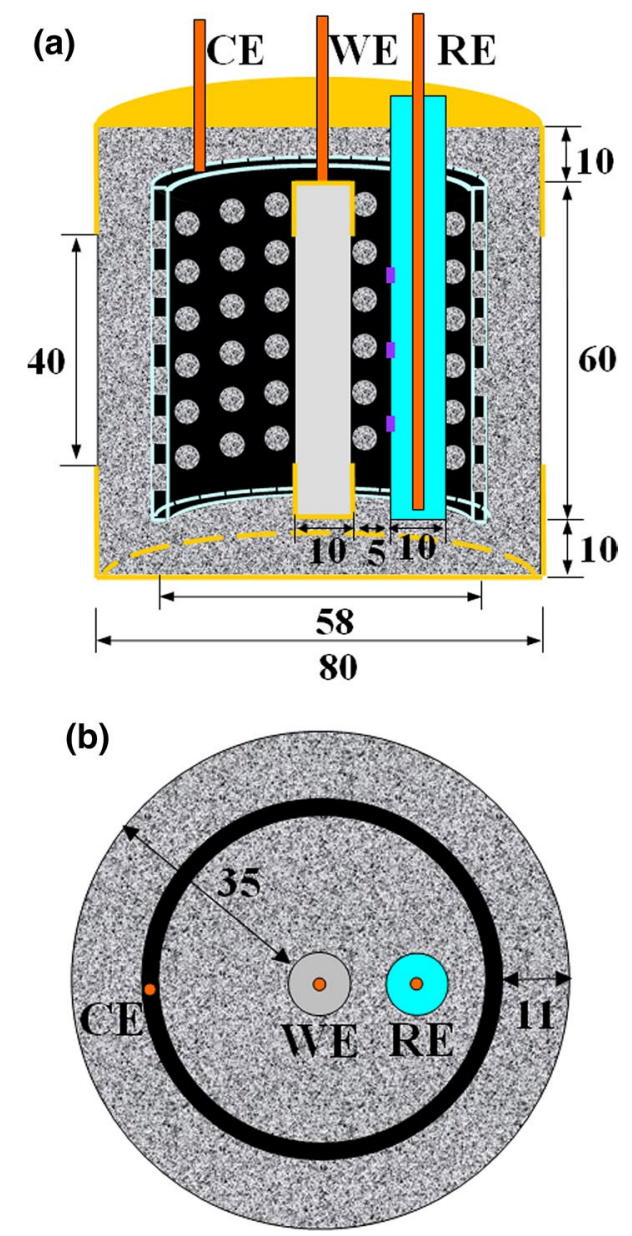

Fig. 1 Schematic diagram of the electrode system for RC samples: a side sectional view, $\mathbf{b}$ top sectional view 


\subsection{Corrosion Tests}

Long-term immersion test and wet-dry alternate test were carried out to simulate the corrosion process of RC in immersion and tidal zones of marine, respectively. In order to accelerate the corrosion initiation and propagation of rebar without changing the corrosion evolution mechanism, several common acceleration methods including the use of impressed current, admixed chlorides, increasing the chloride concentration and rising the environmental temperature are avoided to adopt [31-33]. As a substitute, the method of increasing the porosity of concrete (using the high water/cement ratio of 0.5 ) and reducing the thickness of the concrete cover layer $(35 \mathrm{~mm})$ was adopted to accelerate the chloride diffusion process, which will accelerate the corrosion of rebar. The electrolyte used was the artificial sea water of $3.5 \% \mathrm{NaCl}$ solution, and the temperature is controlled at $25^{\circ} \mathrm{C}$. For the long-term immersion test, the RC cylindrical samples were completely immersed in $3.5 \% \mathrm{NaCl}$ solution for 160 days. For the tidal test, a wet-dry cycle including immersion in $3.5 \% \mathrm{NaCl}$ solution for $2 \mathrm{~h}$ and dry in air for $22 \mathrm{~h}$ was set to simulate the high tidal zone using a simulated tidal experimental device [34].

\subsection{Electrochemical Measurements}

During the long-term immersion and tidal tests, the corrosion potential $\left(E_{\text {corr }}\right)$ and electrochemical impedance spectroscopy (EIS) were monitored using a HA-151A potentiostat/galvanostat and the Gamry reference 600 electrochemical workstation, respectively. EIS measurements were performed over the frequency range from $100 \mathrm{kHz}$ to $10 \mathrm{mHz}$ with a $10-\mathrm{mV}$ amplitude signal at the open-circuit potential. The EIS results were fitted by ZSimpWin software with the equivalent circuit models.

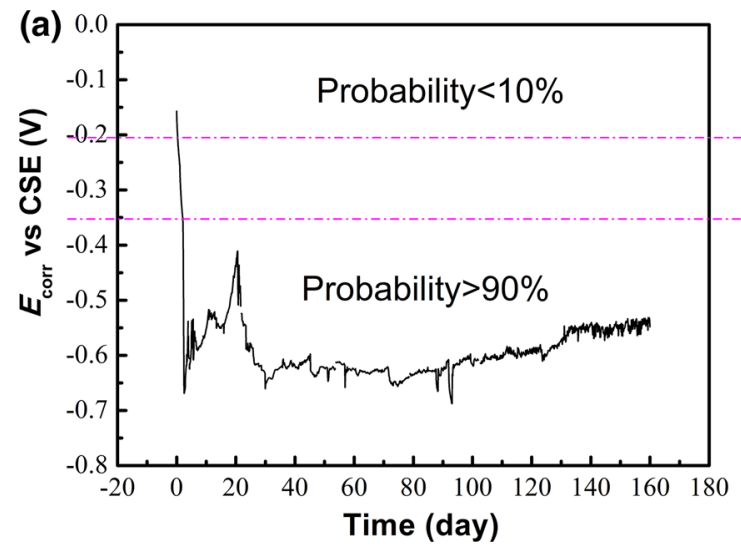

\subsection{Corrosion Morphology}

After the corrosion tests, the rebar samples were taken out from the concrete by cutting the concrete with a grinding machine. Then the surface morphologies of rebar with corrosion products were observed by a ZEISS stemi 508 stereomicroscope. The cross-sectional morphologies were observed by using a HITACHI S3400 N scanning electronic microscope (SEM). Before SEM observation, the samples were mounted with epoxy resin leaving only one exposed crosssectional surface, and they were mechanically ground with 80 down to 1000 -grit $\mathrm{SiC}$ paper and polished with $2.5 \mu \mathrm{m}$ diamond paste. In addition, after removing the corrosion product with a solution of $3.5 \mathrm{~g}$ hexamethylene tetramine $\left(\mathrm{C}_{6} \mathrm{H}_{12} \mathrm{~N}_{4}\right)$ and $500 \mathrm{ml}$ of $37 \% \mathrm{HCl}$ and $500 \mathrm{ml}$ of deionized water [35], the surface morphologies of the rebar substrate were also observed by both the SEM and stereomicroscope.

\section{Results}

\subsection{Evolution of $E_{\text {corr }}$}

Figure 2a, $\mathrm{b}$ shows the evolution of $E_{\text {corr }}$ for the RC samples in the simulated immersion zone and tidal zone, respectively. According to the ASTM C876-91 standard as shown in Table 1 [36], the corrosion probability can be distinguished by the value of $E_{\text {corr }}$. For the RC samples in immersion zone, the initial $E_{\text {corr }}$ was $-0.157 \mathrm{~V}$ vs cupric sulfate electrode (CSE), indicating that the rebar was in passive state, while it decreased sharply to $-0.65 \mathrm{~V}$ vs CSE after 2.5 days of immersion, corresponding to the occurrence of corrosion. It could be ascribed to the penetration of sea water to the rebar surface through the pores in concrete cover. After that, $E_{\text {corr }}$ always located in the high corrosive region below $-0.35 \mathrm{~V}$ vs CSE and presented fluctuation variation, indicating that the rebar was still in active corrosion condition during

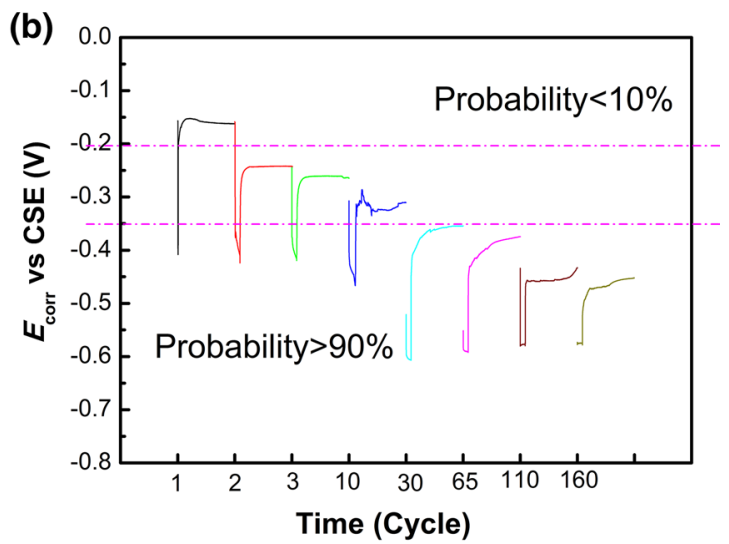

Fig. $2 E_{\text {corr }}$ evolution of rebar in concrete: a immersion zone, b tidal zone 
Table 1 Guidelines for corrosion potential data interpretation

$E_{\text {corr }}$ versus CSE (V)

Corrosion probability $(\%)$

$>-0.20$

-0.35 to -0.20

$<-0.35$

long-term immersion. For the RC samples under tidal condition, $E_{\text {corr }}$ changed regularly in a wet-dry tidal cycle. In each cycle, $E_{\text {corr }}$ decreased quickly during the $2 \mathrm{~h}$ of immersion process and then increased rapidly when the samples were exposed in air, and finally maintained stable during the $22 \mathrm{~h}$ of drying process. In addition, $E_{\text {corr }}$ of respective immersion or drying process also changed with corrosion cycles. For the immersion process, $E_{\text {corr }}$ was about $-0.4 \mathrm{~V}$ vs CSE in the initial three cycles and then decreased to $-0.46 \mathrm{~V}$ vs CSE until 10 cycles, after that it further decreased to $-0.6 \mathrm{~V}$ vs CSE after 30 cycles. For the drying process, $E_{\text {corr }}$ decreased gradually from $-0.16 \mathrm{~V}$ vs CSE at 1 cycle to $-0.46 \mathrm{~V}$ vs CSE at 160 cycles. This decrease in $E_{\text {corr }}$ in both immersion and drying processes also means the increase in corrosion probability with corrosion cycles.

\subsection{EIS Results}

Figure 3a-f shows the evolution of EIS plots for the RC samples in the simulated immersion and tidal zones, respectively. In the tidal zone, the EIS were measured during the rising tidal process when the RC samples were immersed in solution for $2 \mathrm{~h}$ of each wet-dry cycle. It shows that the Nyquist plot and Bode $|Z|$ plot present a straight line in the low frequency region (Fig. 3a, b, d, e), and the phase angle keeps horizontal in the low frequency region (Fig. 3c, f) in the immersion zone for the initial 2 days and the tidal zone for 1 cycle, which implies that rebar was in a passive state [37]. Then, under the conditions of 2.5 days of immersion and 2 cycles of tidal effect, both the real and imaginary parts of impedance, the $|Z|$ and phase angle in the low frequency decrease obviously, which corresponds to the initiation of corrosion.

To compare the corrosion rate of two steels, the EIS results were fitted using the equivalent circuit (EC) models shown in Fig. 4, in which $R_{\mathrm{s}}$ represents the electrolyte

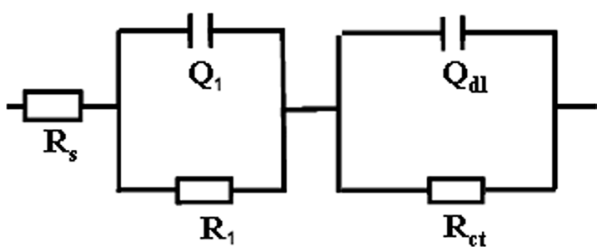

Fig. 4 Schematic diagram of the equivalent circuit model
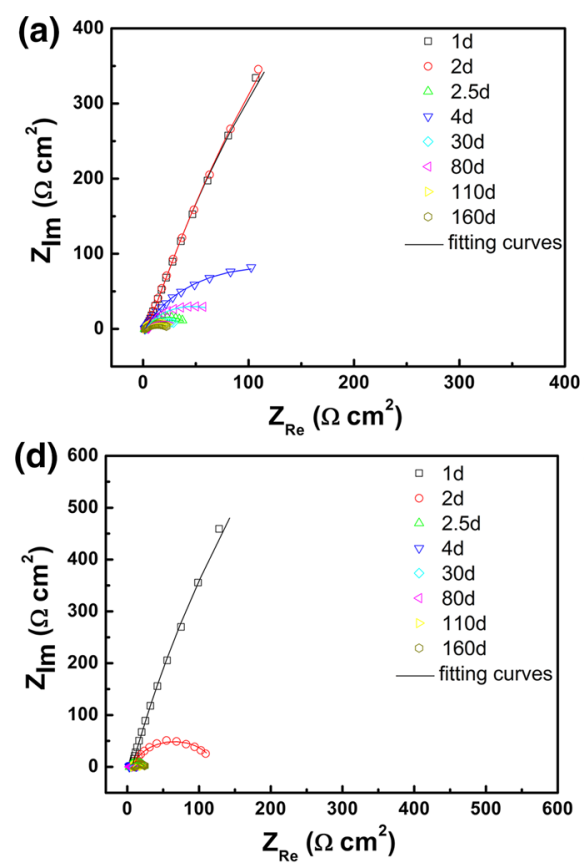
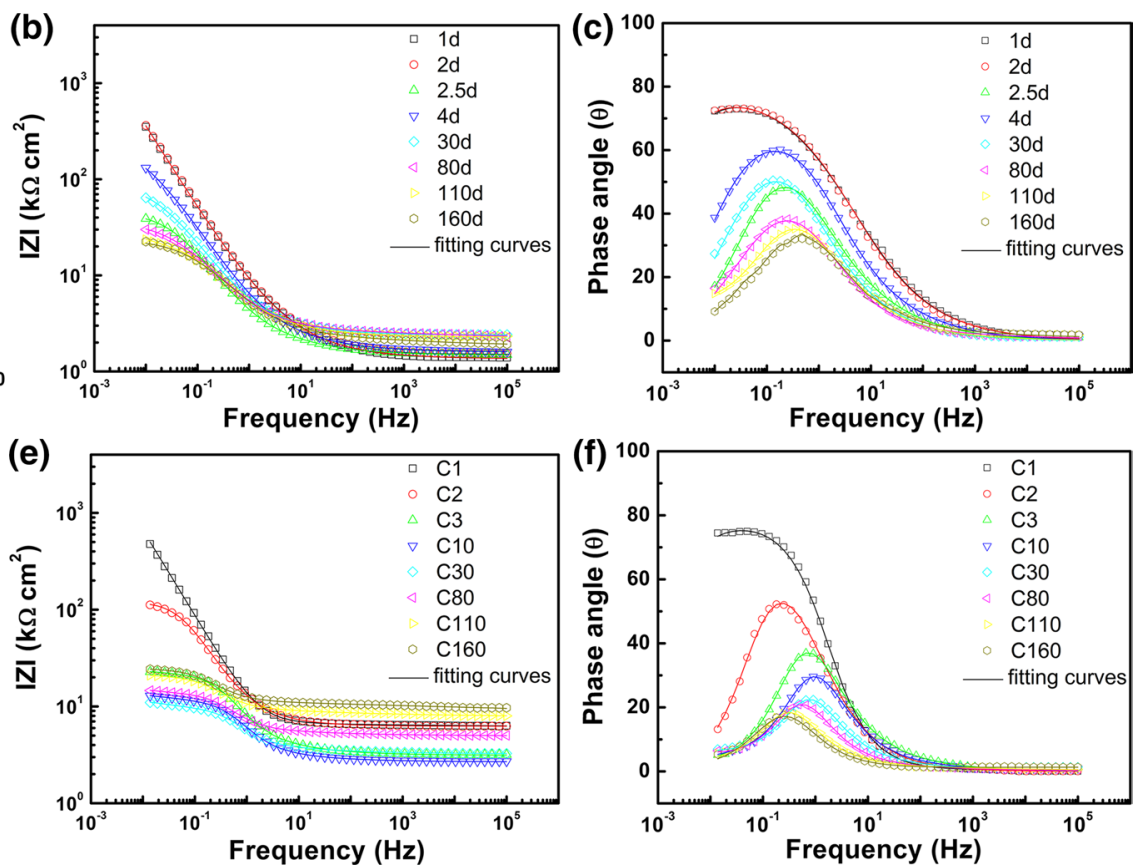

Fig. 3 Evolution of EIS plots of rebar in concrete: a-c simulated immersion zone, $\mathbf{d}-\mathbf{f}$ simulated tidal zone, $\mathbf{a}, \mathbf{d}$ Nyquist plots, $\mathbf{b}$, e Bode modulus plots, $\mathbf{c}, \mathbf{f}$ Bode phase angle plots 
Table 2 Fitting results of EIS data of rebar in immersion zone

\begin{tabular}{lllllllll}
\hline Days & $R_{\mathrm{s}}\left(\mathrm{k} \Omega \mathrm{cm}^{2}\right)$ & $\begin{array}{l}\mathrm{CPE}_{1^{-}} Y_{0} \\
\left(\Omega^{-1} \mathrm{~cm}^{-2} \mathrm{~s}^{-}\right. \\
\mathrm{n} 1)\end{array}$ & $n_{1}$ & $R_{1}\left(\mathrm{k} \Omega \mathrm{cm}^{2}\right)$ & $\begin{array}{l}\mathrm{CPE}_{\mathrm{dl}} Y_{0} \\
\left(\Omega^{-1} \mathrm{~cm}^{-2} \mathrm{~s}^{-}\right. \\
\mathrm{ndl})\end{array}$ & $n_{\mathrm{dl}}$ & $R_{\mathrm{ct}}\left(\mathrm{k} \Omega \mathrm{cm}^{2}\right)$ & $\chi^{2} \times 10^{4}$ \\
\hline 1 & 1.353 & 0.105 & 0.467 & 3857 & 0.036 & 0.906 & 2719 & 3.259 \\
2 & 1.354 & 0.119 & 0.450 & 2817 & 0.035 & 0.895 & 3309 & 3.698 \\
2.5 & 1.478 & 0.208 & 0.453 & 1.526 & 0.082 & 0.796 & 42.34 & 0.310 \\
4 & 1.600 & 0.150 & 0.455 & 1.305 & 0.046 & 0.788 & 226.4 & 1.751 \\
30 & 2.397 & 0.165 & 0.502 & 1.069 & 0.065 & 0.766 & 87.46 & 1.180 \\
80 & 2.228 & 0.412 & 0.218 & 1.124 & 0.080 & 0.695 & 33.69 & 1.581 \\
110 & 2.256 & 0.667 & 0.296 & 2.895 & 0.084 & 0.693 & 23.20 & 4.334 \\
160 & 1.769 & 0.570 & 0.174 & 3.133 & 0.076 & 0.706 & 20.45 & 1.010 \\
\hline
\end{tabular}

Table 3 Fitting results of EIS data of rebar in tidal zone

\begin{tabular}{lllllllcc}
\hline Cycles & $R_{\mathrm{s}}\left(\mathrm{k} \Omega \mathrm{cm}^{2}\right)$ & $\begin{array}{l}\mathrm{CPE}_{1}-Y_{0} \\
\left(\Omega^{-1} \mathrm{~cm}^{-2} \mathrm{~s}^{-\mathrm{n} 1}\right)\end{array}$ & $n_{1}$ & $R_{1}\left(\mathrm{k} \Omega \mathrm{cm}^{2}\right)$ & $\begin{array}{l}\mathrm{CPE}_{\mathrm{dl}} Y_{0} \\
\left(\Omega^{-1} \mathrm{~cm}^{-2} \mathrm{~s}^{-\mathrm{ndl}}\right)\end{array}$ & $n_{\mathrm{dl}}$ & $R_{\mathrm{ct}}\left(\mathrm{k} \Omega \mathrm{cm}^{2}\right)$ & $\chi^{2} \times 10^{4}$ \\
\hline $\mathrm{C} 1$ & 6.422 & 0.440 & 0.541 & 3457 & 0.023 & 0.894 & 4098 \\
$\mathrm{C} 2$ & 6.259 & 0.093 & 0.557 & 5.183 & 0.032 & 0.911 & 110.5 \\
$\mathrm{C} 3$ & 3.127 & 0.206 & 0.415 & 5.889 & 0.049 & 0.912 & 15.37 \\
$\mathrm{C} 10$ & 3.221 & 0.424 & 0.369 & 6.241 & 0.097 & 0.925 & 4.635 \\
$\mathrm{C} 30$ & 4.866 & 0.454 & 0.340 & 9.271 & 0.096 & 0.921 & 6.323 \\
$\mathrm{C} 80$ & 8.331 & 0.357 & 0.297 & 12.43 & 0.095 & 0.912 & 8.418 \\
$\mathrm{C} 110$ & 9.386 & 0.286 & 0.241 & 16.41 & 0.109 & 0.919 & 10.07 \\
$\mathrm{C} 160$ & 9.766 & 0.277 & 0.244 & 18.38 & 0.118 & 0.938 & 9.607 \\
\hline
\end{tabular}

resistance of the RC samples, $R_{1}$ the surface film resistance or rust resistance, and $Q_{1}$ the constant phase element of the passive film or rust layer, $R_{\mathrm{ct}}$ the charge transfer resistance, $Q_{\mathrm{dl}}$ the constant phase element of the electric double layer. The fitting curves are presented as the solid lines for each plot in Fig. 3, and the fitting parameters are listed in Tables 2 and 3 for immersion and tidal zones, respectively. The mean square errors of $\chi^{2}$ are all in the order of magnitude $10^{-4}$, which illustrates the rationality of the fitting results.

According to the fitting results, $R_{\mathrm{s}}$ in simulated immersion and tidal zones was compared as shown in Fig. 5. For the immersion zone, the initial $R_{\mathrm{s}}$ slightly increased before 30 days and then decreased in the following days. It is obvious that the overall change of $R_{\mathrm{s}}$ is just in the range of 1.35 to $2.4 \mathrm{k} \Omega \mathrm{cm}^{2}$ during the whole immersion time of 160 days. While for the simulated tidal zone, $R_{\mathrm{s}}$ sharply decreased in the first 3 cycles, and then, it gradually increased with immersion cycles. The final value of $R_{\mathrm{s}}$ reached $9.8 \mathrm{k} \Omega \mathrm{cm}^{2}$ after 160 wet-dry cycles. As the reference electrode was embedded at $5 \mathrm{~mm}$ from the central rebar, $R_{\mathrm{s}}$ can reflect the chloride ion content in the concrete pore and the dry/wet condition of concrete layer from the reference electrode to the rebar surface. Obviously, $R_{\mathrm{s}}$ will decrease with increasing electrolyte content in the concrete pore and the humidity of concrete layer, and it will increase with the drying of

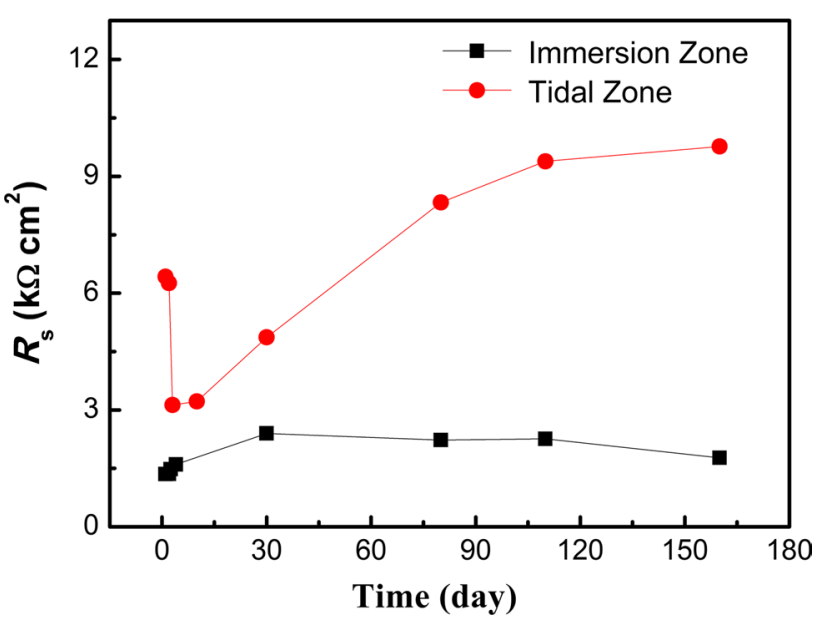

Fig. 5 Comparison of $R_{\mathrm{s}}$ in immersion and tidal zones

concrete layer or the deposition of insoluble and insulating corrosion product in the pore of concrete. Therefore, the relative stable $R_{\mathrm{s}}$ for immersion zone indicates the concrete layer near rebar was always saturated by the sea water with a fixed ionic concentration, and the deposition of corrosion product in the pore of concrete can just cause a slightly increase for $R_{\mathrm{s}}$. By comparison, the obvious decrease in $R_{\mathrm{s}}$ 
during the initial stage for tidal zone implies the concrete layer was gradually wetted by the sea water, and the subsequent increase in $R_{\mathrm{s}}$ with immersion cycles should attribute to the massive deposition of corrosion product in the pore of concrete with the dry/wet alternation process.

Figure 6 shows the evolution of $R_{1}$ for the simulated immersion and tidal zones. It clearly shows that the variation in $R_{1}$ for the two zones is quite similar. The initial $R_{1}$ value for both zones was very high, corresponding to the passive state of rebar in concrete due to the formation of the passive film during the curing process [38]. However, $R_{1}$ sharply decreased in the first 2.5 days for immersion zone and in the first 2 cycles for tidal zone, respectively. This should correspond to the breakdown of the passive film and the initiation of corrosion. After that, both of $R_{1}$ slightly increased with time, corresponding to the gradual accumulation of corrosion product on the rebar surface. Moreover, it is obvious that $R_{1}$ in the immersion zone is always smaller than that in the tidal zone during the followed long-term corrosion, which means the thickness of the corrosion product layer for rebar in the immersion zone is probably thinner than that in the tidal zone.

According to the fitting results of $R_{\mathrm{ct}}$, the corrosion current density of rebar can be calculated by the Stern-Geary equation:

$I_{\text {corr }}=B / R_{\mathrm{ct}}$,

where $I_{\text {corr }}$ represents the corrosion current density and $B$ the "Stern-Geary constant." The value of $52 \mathrm{mV}$ and $26 \mathrm{mV}$ is often used in the calculation of $B$ for rebar in the passive and active states, respectively [39, 40]. According to the criteria for estimating the corrosion of rebar, as shown in Table 4 [41], the rebar is in passive state when $I_{\text {corr }}<0.1 \mu \mathrm{A} \mathrm{cm}^{-2}$. Therefore, the passive and active states can be distinguished by the value of $I_{\text {corr }}$

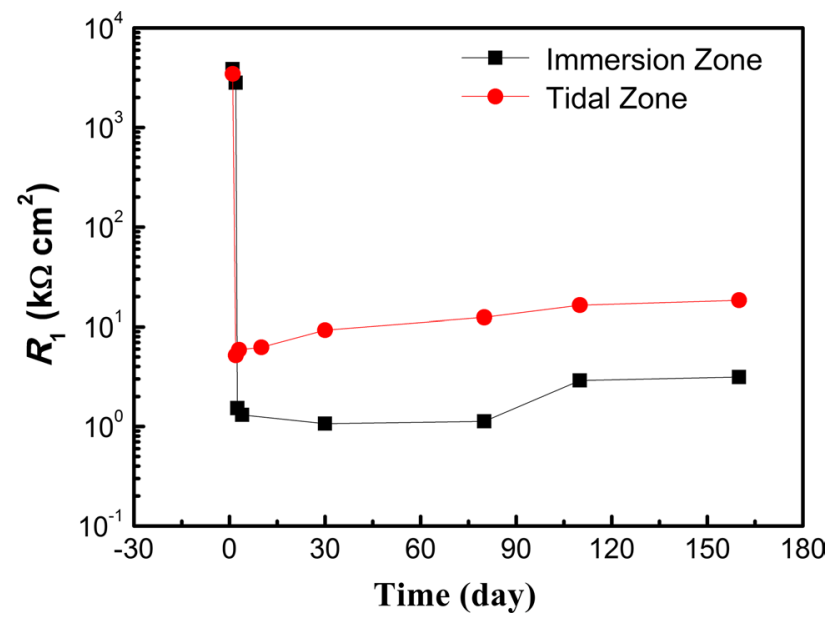

Fig. 6 Comparison of $R_{1}$ in immersion and tidal zones
Table 4 Criteria for estimating rebar corrosion conditions

\begin{tabular}{ll}
\hline Corrosion rate $\left(\mu \mathrm{A} \mathrm{cm}^{-2}\right)$ & Extent of corrosion \\
\hline$I_{\text {corr }}<0.1$ & Passive state \\
$0.1<I_{\text {corr }}<0.5$ & Low-to-moderate corrosion \\
$0.5<I_{\text {corr }}<1.0$ & Moderate-to-high corrosion \\
$I_{\text {corr }}>1.0$ & High corrosion \\
\hline
\end{tabular}

Figure 7 shows the evolution of $I_{\text {corr }}$ with time in the simulated immersion and the tidal zones. According to the criteria, it is verified by the value of $I_{\text {corr }}$ that the rebar of both zones was in passive state initially, and then, the passive state was quickly diminished after 2.5 days for the immersion zone and 2 cycles for the tidal zone, respectively. After that, the $I_{\text {corr }}$ of the immersion zone gradually increased with time from low corrosion rate region to high corrosion rate region, and it kept at $1.27 \mu \mathrm{A} \mathrm{cm}^{-2}$ as a stable value after 110 days. However, the $I_{\text {corr }}$ of the tidal zone quickly reached the high corrosion rate region after corrosion occurred, and then, it slowly decreased with time, and finally, it reached a stable corrosion rate of $2.71 \mu \mathrm{A} \mathrm{cm}^{-2}$ after 110 cycles. The long-term corrosion rate of rebar in tidal zone is two times higher than that in immersion zone.

Figure 8 shows the evolution of EIS plots with wet-dry cycles in simulated tidal zone. According to the principle of EIS, the $|Z|$ at high frequency region can be regarded as the electrolyte resistance $\left(R_{\mathrm{s}}\right)$ of the RC samples, and the $|Z|$ at low frequency region can be regarded as the sum of $R_{\mathrm{s}}$ and the polarization resistance $\left(R_{\mathrm{p}}\right)$ of rebar $[42,43]$. Hence, the difference between $|Z|$ at low frequency and $|Z|$ at high frequency should correspond to the $R_{\mathrm{p}}$ which reflects the corrosion rate of rebar [42]. As for the impedance spectra measured in this experiment, the $|Z|$ at frequency of $10 \mathrm{kHz}$ is assumed as $R_{\mathrm{S}}$ and that at $10 \mathrm{mHz}$ as the sum of $R_{\mathrm{S}}$ and

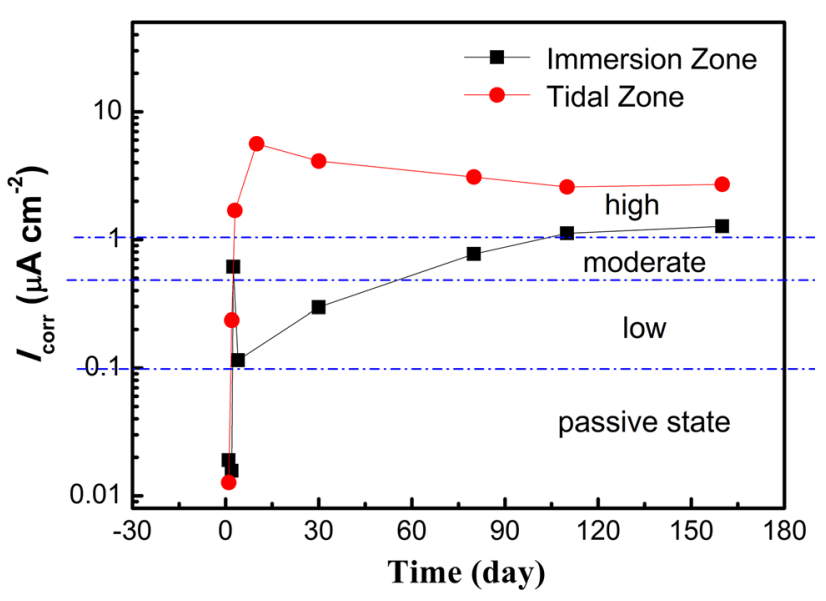

Fig. 7 Comparison of $I_{\text {corr }}$ in immersion and tidal zones 

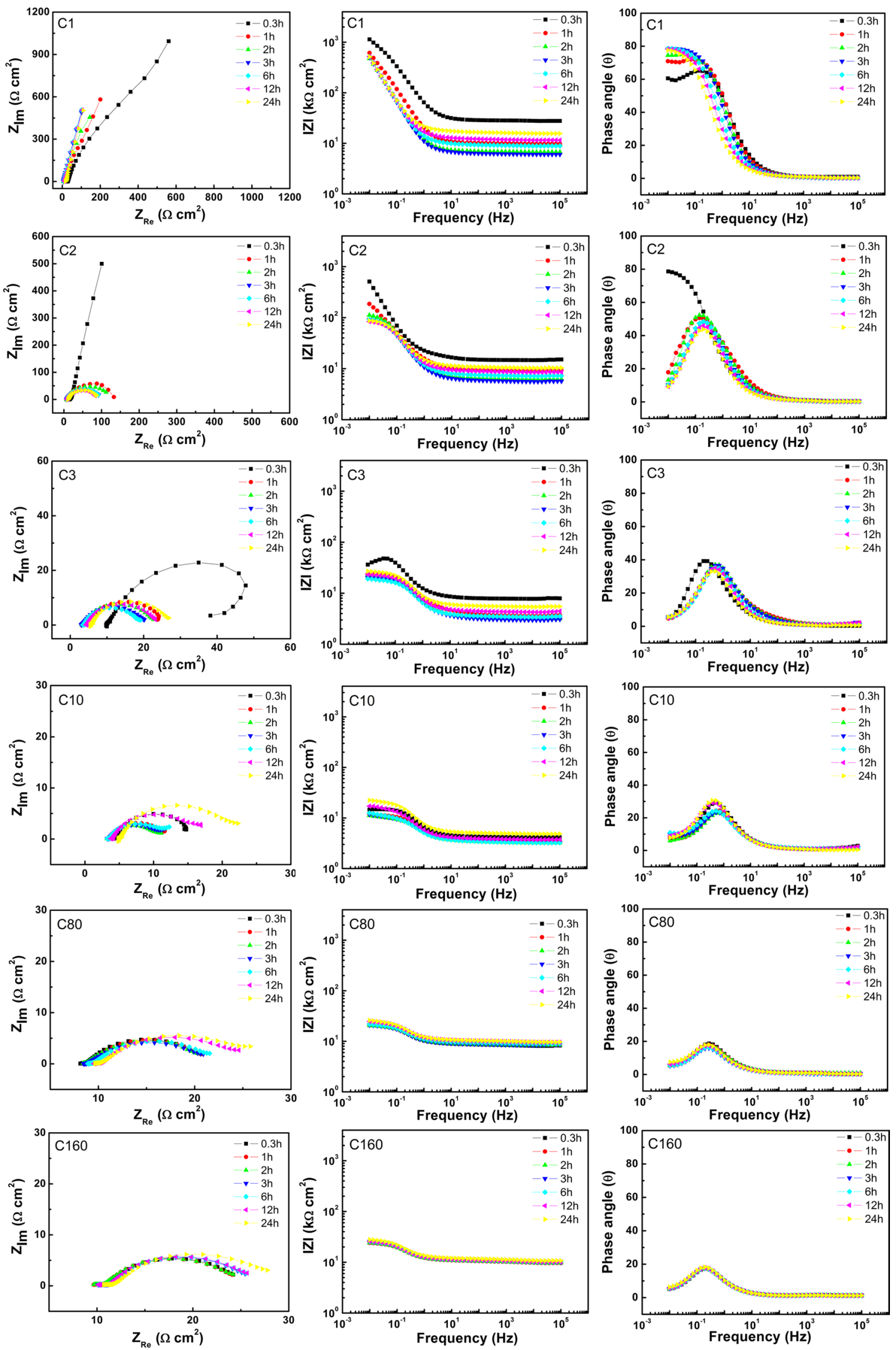

Fig. 8 Evolution of EIS plots with wet-dry process in tidal zone for different cycles 
$R_{\mathrm{p}}$. Thus, the difference of $|Z|$ between $10 \mathrm{mHz}$ and $10 \mathrm{kHz}$ is defined as $R_{\mathrm{p}}$.

Figure 9 shows the evolution of $R_{\mathrm{S}}$ with time in different tide cycles. In the first three cycles, $R_{\mathrm{s}}$ sharply decreased in the immersion stage and reached a lowest value at $3 \mathrm{~h}$, and then, it gradually increased during the drying stage. According to the tidal settings, the RC samples were immersed in $3.5 \% \mathrm{NaCl}$ solution in the initial $2 \mathrm{~h}$ and dried in air in the followed $22 \mathrm{~h}$ for a tidal cycle. In the $2 \mathrm{~h}$ of immersion stage, the artificial sea water permeated into the pore of concrete, which causes the decrease in $R_{\mathrm{s}}$ of the concrete layer. During the drying process, the water gradually evaporated from outside to inside of the concrete layer, which influences the $R_{\mathrm{S}}$ from two aspects. On the one hand, the permeated sea water was gradually concentrated with the drying of concrete, which leads to the increase in ion concentration and consequently the decrease in the $R_{\mathrm{s}}$. On the other hand, the following loss of water content in the concrete by evaporation causes the increase in $R_{\mathrm{s}}$, because some amount of free

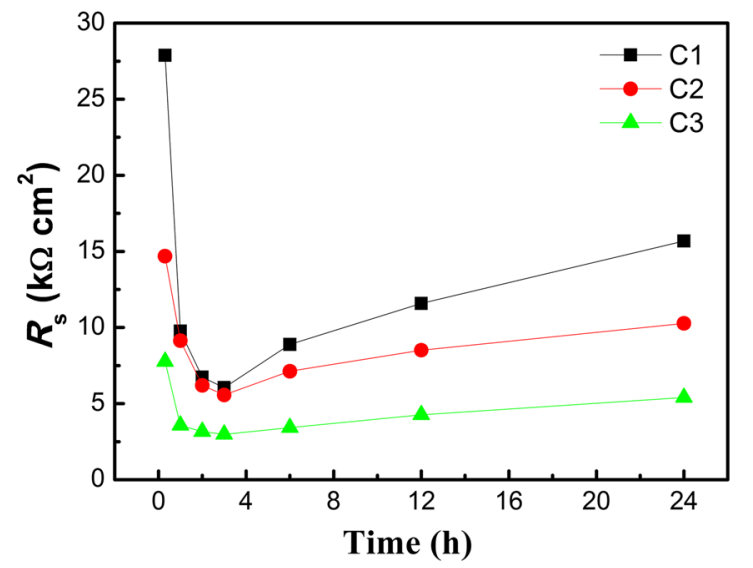

Fig. 9 Evolution of $R_{\mathrm{s}}$ with time in different fluctuating tide cycles

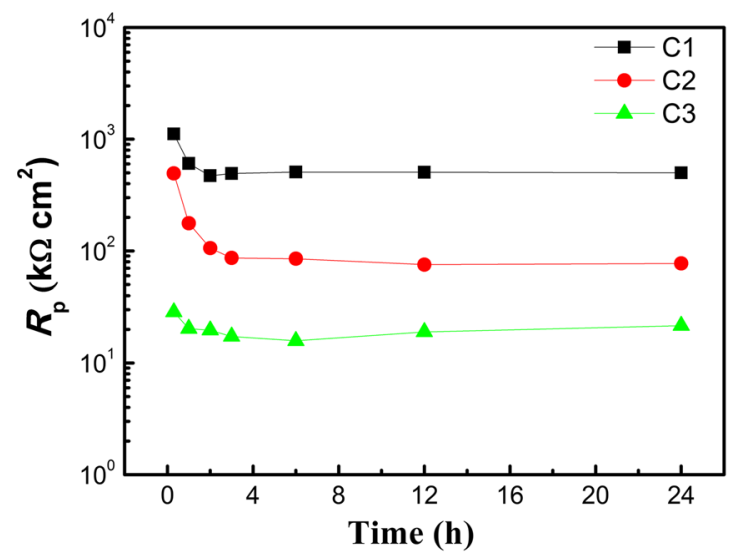

Fig. 10 Evolution of $R_{\mathrm{p}}$ with time in different fluctuating tide cycles water existing in the concrete is a prerequisite of maintaining the ionic conductivity. Therefore, the first decrease in $R_{\mathrm{S}}$ from 2 to $3 \mathrm{~h}$ can be ascribed to the ionic concentration, while that the increase in $R_{\mathrm{s}}$ after $3 \mathrm{~h}$ should be caused by lack of water in concrete during the drying process.

However, the change of $R_{\mathrm{s}}$ in one tidal cycle is not obvious after 10 cycles. As the permeating rate of sea water to the concrete is much faster than that of the drying rate, with the increase in the tidal cycles, the ion concentration in concrete pore and the relative humidity of concrete layer near central rebar surface will become stable. Therefore, $R_{\mathrm{S}}$ in one tidal cycle becomes more stable with extending the dry-wet cycles.

Figure 10 shows the evolution of $R_{\mathrm{p}}$ with time in different tidal cycles. It shows that, for the initial three cycles, $R_{\mathrm{p}}$ also decreased in the first $3 \mathrm{~h}$ and then kept as stable in the following drying process. After 10 cycles, $R_{\mathrm{p}}$ presented a slight decrease during the immersion stage and a slight increase during the whole drying stage in one cycle. As the $R_{\mathrm{p}}$ can
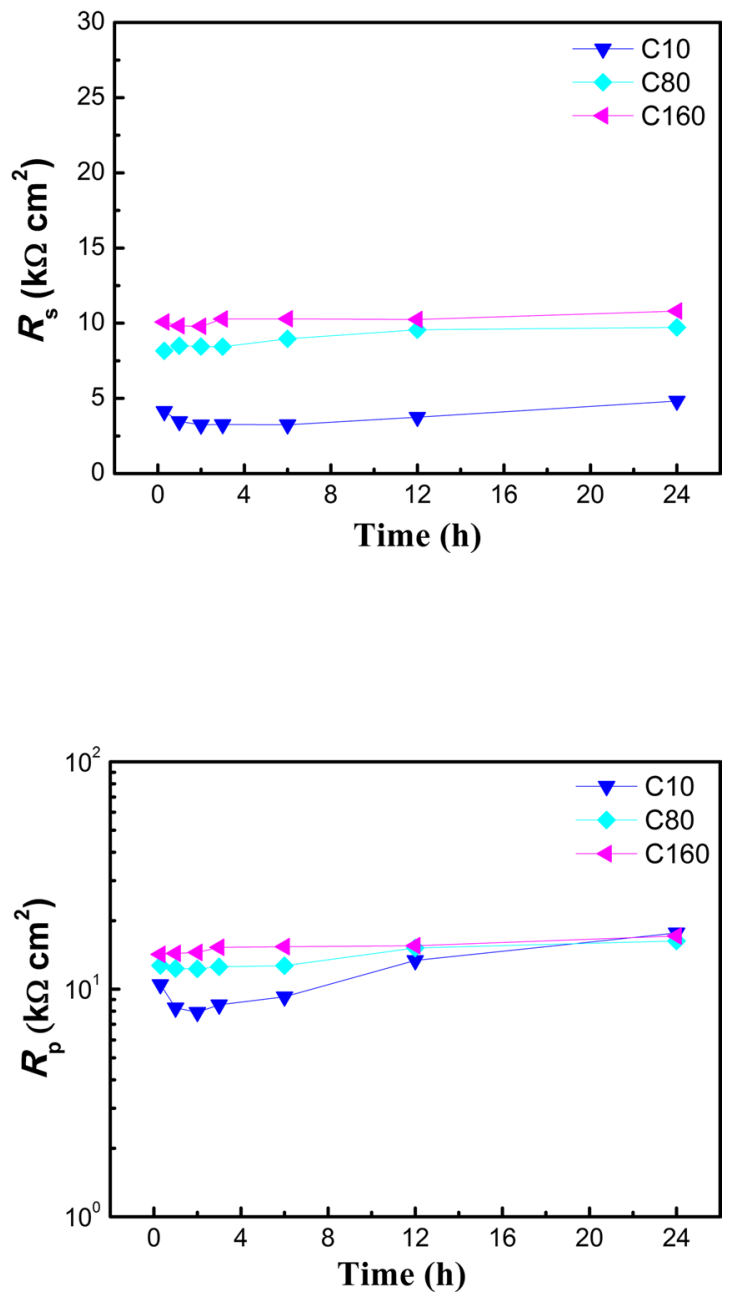
reflect the corrosion rate of rebar, it is proved that the corrosion rate of rebar in tidal zone increases quickly during the immersion stages and keeps stable during the drying process within the initial 3 cycles. However, the corrosion rate does not change obviously in each of the wet-dry cycles hereafter. In addition, the change of $R_{\mathrm{p}}$ with cycles firstly presented a decrease, then an increase and then a stable value during the whole test, which is consistent with the change of $I_{\text {corr }}$ shown in Fig. 7.

\subsection{Corrosion Morphology}

Figure 11 shows the corrosion morphologies of rebar surface with corrosion product obtained by using stereomicroscope after corrosion for 160 days in simulated immersion and tidal zones. For the immersion zone, the corrosion product covers most of the surfaces of rebar, and only small part of the rebar matrix is still exposed, as shown in Fig. 11a. It indicates that the corrosion of rebar has not extended to the entire surface. The corrosion extent of rebar is more severe at some local regions, as shown in the enlarged view in Fig. 11b, which reveals that rebar in the immersion zone occurs non-uniform corrosion. For the tidal zone, the surface of rebar looks more uneven than that for the immersion zone, as shown in Fig. 11c. Moreover, some external rust layer had been peeled off in the process of removing concrete from the outside of rebar, as shown in the enlarged view in Fig. 11d. This implies the corrosion of the RC samples submitted in the tidal zone is more serious and uneven than that in immersion zone.

Figure 12 shows the surface morphologies of rebar matrix after removing the rust for the RC samples in simulated immersion and tidal zones for 160 days, respectively. It can be observed that some shallow corrosion spots and deep corrosion pits appeared at local regions for immersion zone and tidal zone, respectively. This indicates the corrosion extent of rebar in both zones is non-uniform, and the local pitting corrosion in tidal zone is more severe than in immersion zone.

Figure 13 shows the SEM micromorphologies of the rebar matrix after removing the rust for the RC samples in simulated immersion and tidal zones for 160 days, respectively. It shows that the microcorrosion morphologies for two zones are almost the same. After removing the rust, two matrix phases with obvious contrast exposed on surface. The qualitative element analysis of these two

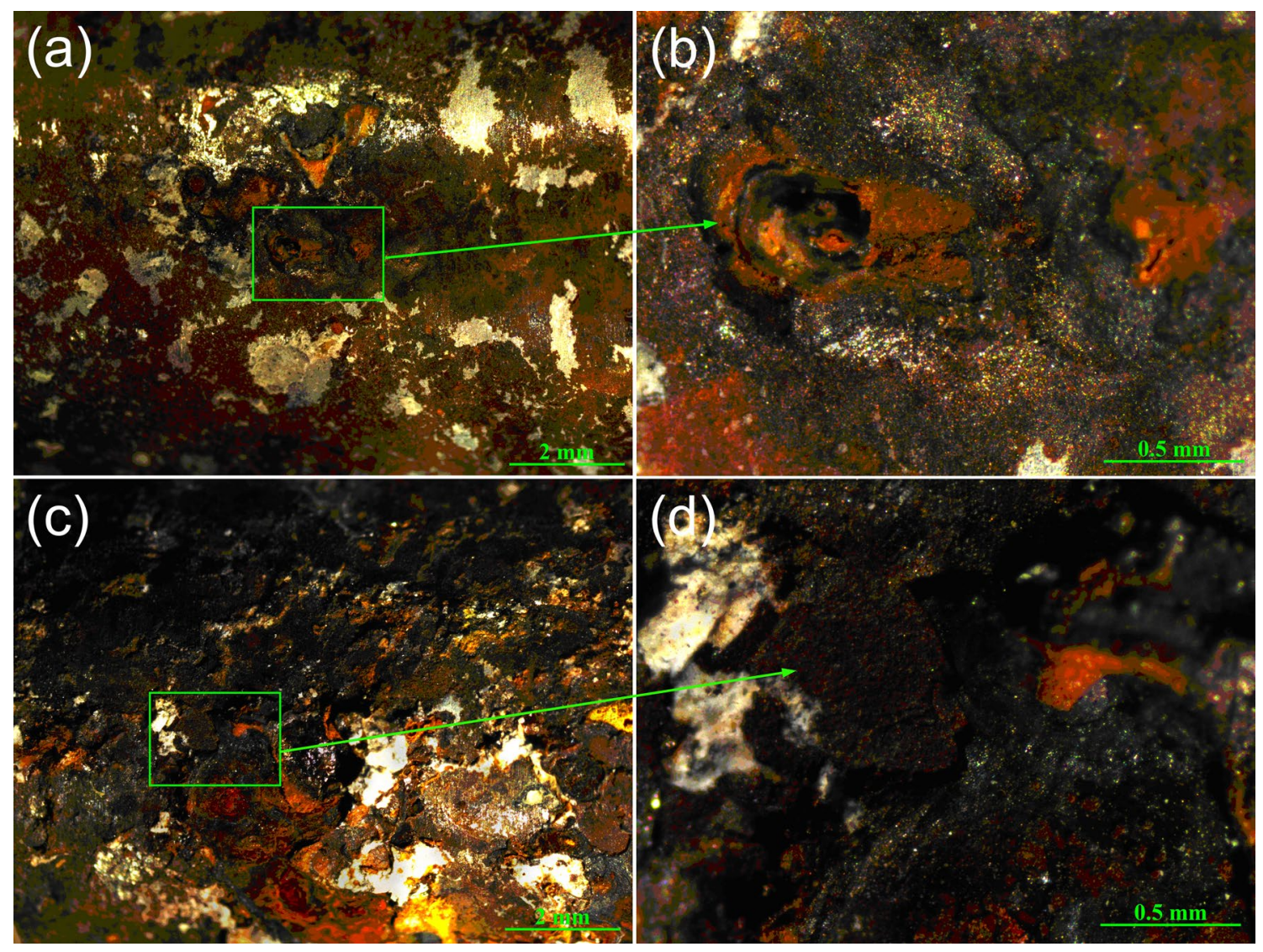

Fig. 11 Macrocorrosion morphologies of rebar surface with corrosion product for immersion zone $\mathbf{a}, \mathbf{b}$, tidal zone $\mathbf{c}, \mathbf{d}$ 

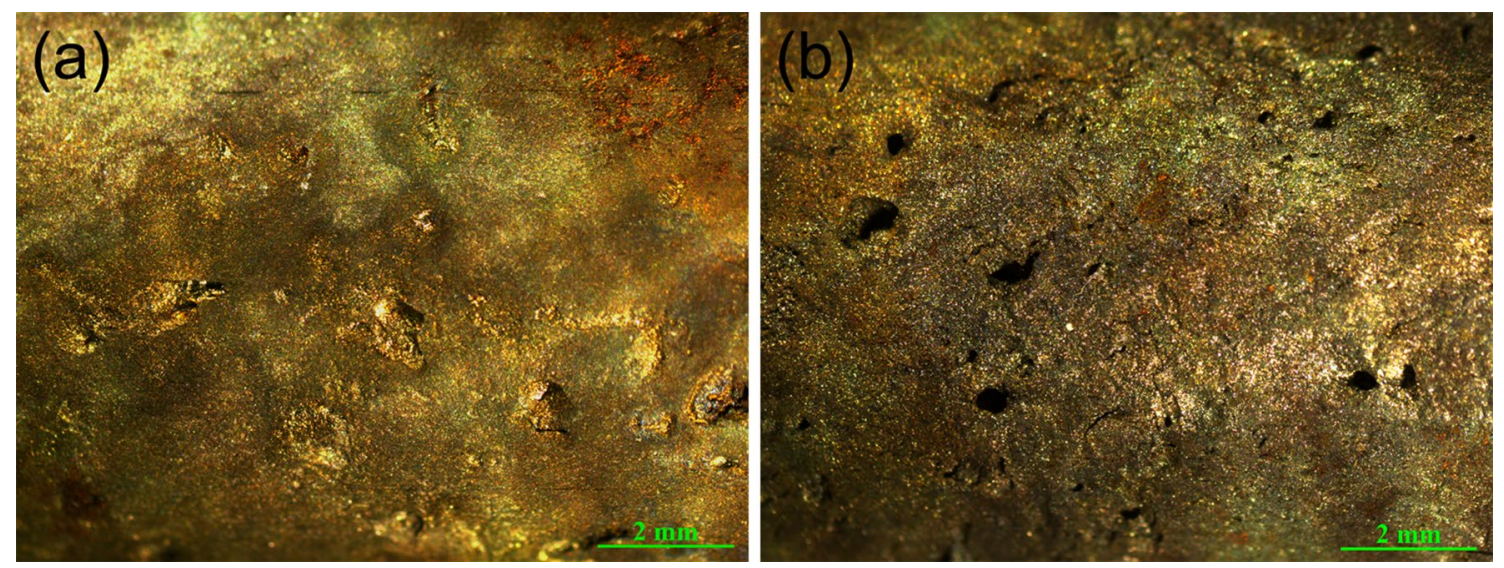

Fig. 12 Macrocorrosion morphologies of rebar matrix after removing the corrosion product for immersion zone a, tidal zone $\mathbf{b}$
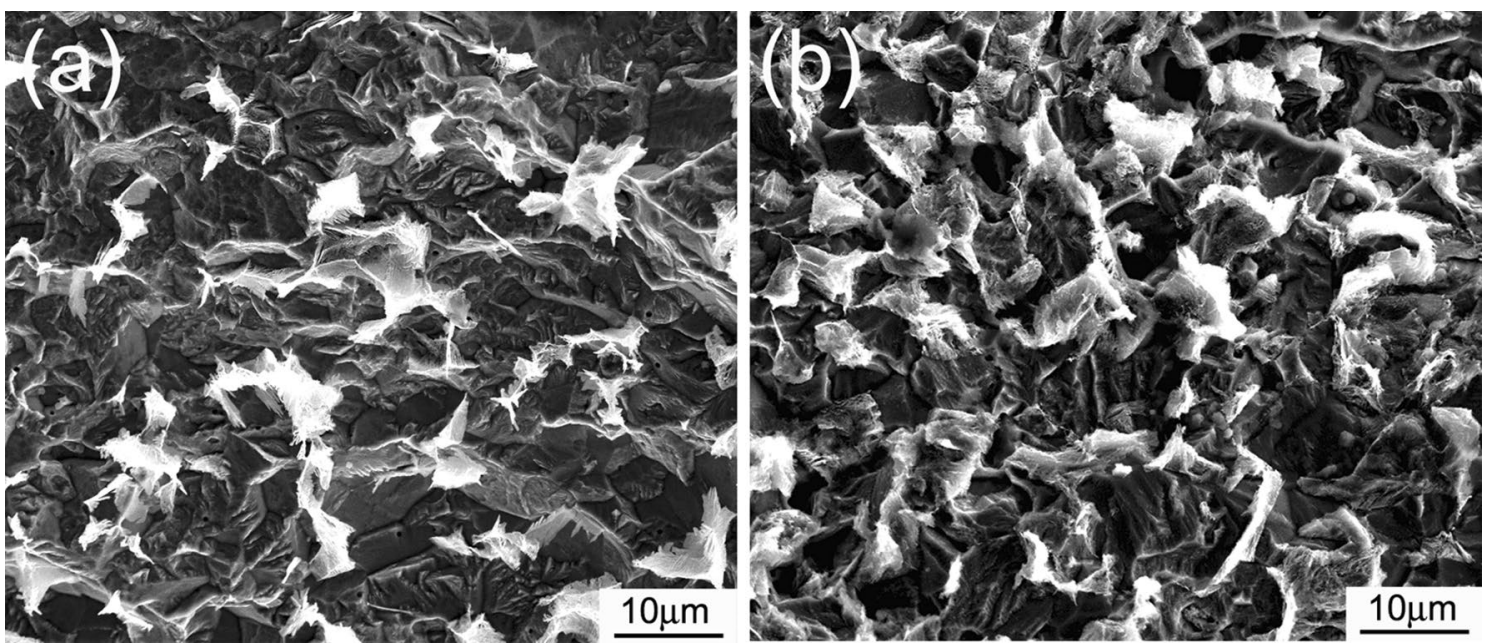

Fig. 13 Microcorrosion morphologies of rebar matrix after removing the corrosion product for immersion zone a, tidal zone $\mathbf{b}$

Table 5 EDS element analysis of different positions (wt $\%$ )

\begin{tabular}{llllll}
\hline Element & $\mathrm{Fe}$ & $\mathrm{C}$ & $\mathrm{Mn}$ & $\mathrm{Si}$ & $\mathrm{O}$ \\
\hline Dark phase & 94.79 & 3.58 & 1.63 & - & - \\
White phase & 63.23 & 22.72 & 1.31 & 0.34 & 12.41 \\
\hline
\end{tabular}

phases by energy-dispersive spectroscopy (EDS) is shown in Table 5. Although the EDS results cannot give the exact content of each element, the difference of Fe and $\mathrm{C}$ contents in different phases can still be used to estimate the phase type. It is identified that the dark phase containing relatively high content of $\mathrm{Fe}$ and low content of $\mathrm{C}$ should be ferrite phase, while the white phase containing relatively high content of $\mathrm{C}$ and low content of $\mathrm{Fe}$ should be cementite phase. Moreover, the $\mathrm{O}$ was also detected in cementite phase, which should be attributed to the residual corrosion product between the gaps of cementite lamella.

Figure 14 shows the cross-sectional morphologies of the rebar in simulated immersion and tidal zones for 160 days. A layer of corrosion product forms on rebar surface for both zones. However, the thickness of corrosion product on rebar in tidal zone is much thicker than that in immersion zone. The largest thickness of corroded rebar is about $0.17 \mathrm{~mm}$ for immersion zone and about $0.6 \mathrm{~mm}$ for tidal zone. It also identifies that the corrosion rate of rebar in tidal zone is much faster than that in immersion zone. 

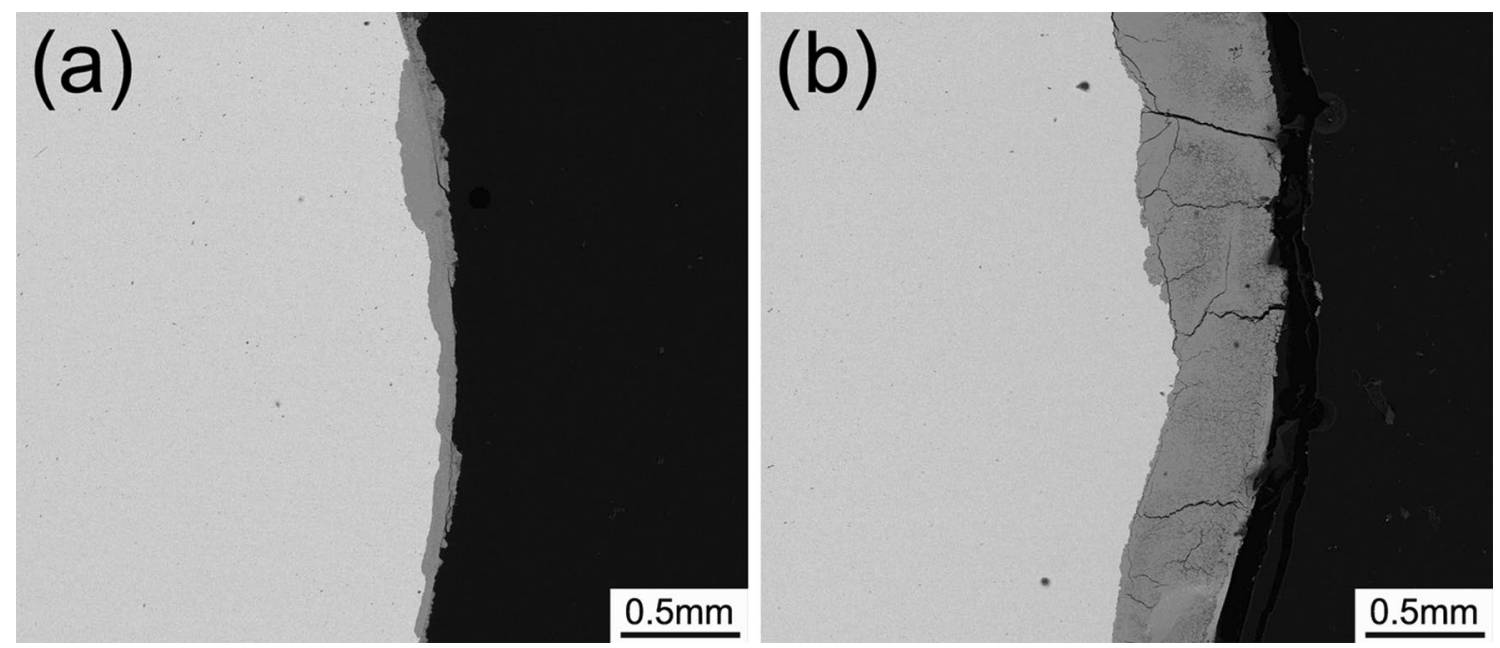

Fig. 14 Cross-sectional corrosion morphologies of rebar in immersion zone $\mathbf{a}$ and tidal zone $\mathbf{b}$

\section{Discussion}

\subsection{Corrosion Evolution Explanation}

According to the change of $I_{\text {corr }}$ with time and the corrosion morphology characteristics, the corrosion evolution of rebar in concrete in two environments can be divided into three stages, which are the passivation in the initial stage, the local pitting in middle stage and the general corrosion in the final stage.

In the initial stage, the passive film initially forms on the rebar surface and maintains in the curing process due to the high alkalinity condition ( $\mathrm{pH} 12.5-13.5)$ of the pore solution in concrete, which can protect the rebar against corrosion [44]. Therefore, the rebar in concrete maintains in passive state during the initial 2 days for the immersion zone and the first cycle and for the tidal zone, respectively.

In the middle stage, with the gradual permeation of $\mathrm{NaCl}$ solution to the rebar surface, once the $\mathrm{Cl}^{-}$concentration surrounding the rebar surface exceeds the threshold of breaking the passive film, pitting will preferentially occur at some local regions where the passive film has defects [45]. The corrosion galvanic couple thus forms between the regions with and without intact passive film. The region with intact passive film would become the cathode to occur oxygen reduction, as shown in reaction (1), while the local region with defects would become the anode to occur the anodic dissolution, as shown in reactions (2-5) [46-48]. Moreover, the $\mathrm{Cl}^{-}$can act as a catalyst for anodic dissolution of iron, as shown in reactions (3) and (4). As $\mathrm{Cl}^{-}$is not consumed in the corrosion reactions, it can make effect persistently on promoting the anodic dissolution of iron. As a result, the occurrence of pitting leads to the corrosion acceleration after 2.5 days in the immersion zone and the second cycle in the tidal zone, respectively.

During the early propagation of pitting, the oxygen reduction outside the pits predominates the cathodic process, and the anodic dissolution of iron in the pits predominates the anodic process. With the continuation of the corrosion process, the environmental difference between inside and outside of the pits gradually becomes apparent. In the pits, the hydrolysis of $\mathrm{Fe}^{2+}$ produces a lot of $\mathrm{H}^{+}$, which causes the gradual acidification of environment. Moreover, to maintain the electric neutrality, a lot of $\mathrm{Cl}^{-}$are electrically transported into the pits, leading to an acceleration of anodic dissolution in the pits [49]. Besides, the large area ratio of the passive region to the pitting region also causes the significant galvanic acceleration on anodic dissolution [50]. As a result, the early propagation of pitting mainly extends to the depth direction to form a deep pit, and the corrosion rate increases very quickly. However, the duration of local pitting stage is very short, which is within 4 days for the immersion zone while 30 cycles for the tidal zone, respectively. This can be estimated by the following decrease in corrosion rate rather than the continuous increase, as shown in Fig. 7.

Cathode reaction:

$\mathrm{H}_{2} \mathrm{O}+1 / 2 \mathrm{O}_{2}+2 \mathrm{e}^{-} \rightarrow 2 \mathrm{OH}$.

Anode reactions:

$\mathrm{Fe} \rightarrow \mathrm{Fe}^{2+}+2 \mathrm{e}$.

$\mathrm{Fe}^{2+}+\mathrm{Cl}^{-} \rightarrow[\text { FeClcomplex }]^{+}$

$[\mathrm{FeClcomplex}]^{+}+2 \mathrm{OH}^{-} \rightarrow \mathrm{Fe}(\mathrm{OH})_{2}+\mathrm{Cl}^{-}$

$\mathrm{Fe}(\mathrm{OH})_{2}+\mathrm{OH}^{-} \rightarrow \gamma-\mathrm{FeOOH}+\mathrm{H}_{2} \mathrm{O}+\mathrm{e}^{-}$. 
Cathode reaction:

$\mathrm{Fe}^{2+}+8 \gamma-\mathrm{FeOOH}+2 \mathrm{e}^{-} \rightarrow 3 \mathrm{Fe}_{3} \mathrm{O}_{4}+4 \mathrm{H}_{2} \mathrm{O}$.

In the final stage, the local pitting to the depth direction cannot be carried out continuously, but gradually changes to general corrosion on the whole rebar surface. This transition may be explained by two reasons. Firstly, with the $\mathrm{Cl}^{-}$gradually transport and concentrate to the rebar surface, it will cause the breakage of the passive film in a large area, which results in the enlargement of exposed area of the rebar matrix. Secondly, with the increase in immersion time, the concrete layer is gradually saturated by sea water, as proved by the change of $R_{\mathrm{s}}$ above. Meanwhile, the concrete pores around the rebar surface are gradually filled with insoluble corrosion products. These will enhance the difficulty of oxygen diffusion to the rebar surface. Thus, the difference of oxygen concentration between outside and inside the pit will decrease, which will also inhibit the extension of local pitting in the depth direction. Moreover, reaction (6) will become the predominant cathodic reduction reaction with the increase in coverage area of the rust on the rebar surface, which also tends to cause a general corrosion of the rebar matrix [26]. Therefore, a layer of rust gradually forms on the whole surface of rebar although the corrosion depth on the whole surface is still different due to the remnant effect of early local pitting corrosion. Under the influence of the above two processes, the corrosion gradually transforms from local pitting to general corrosion, and then, the corrosion rate tends to be stabilized at a high level during the long-term test.

\subsection{Comparison of Corrosion Rate}

The results of EIS monitoring and corrosion morphologies observation also indicate that both the depth of pits and the thickness of corrosion products layer in the tidal zone are higher than those in the immersion zone. Correspondingly, the corrosion rate of the rebar in the tidal zone is also higher than that in the immersion zone for both the local pitting and general corrosion stages. These differences should be attributed to the differences in oxygen and chloride concentrations between the two corrosion environments.

As the diffusion of oxygen to the rebar surface is through the pores in concrete layer, the oxygen concentration on rebar surface is affected by the dry-wet condition of the concrete layer. When the concrete is in solution saturated condition, the oxygen can only diffuse to the rebar surface through the solution in concrete pores. As the maximum oxygen content in water solution is $9 \mathrm{mg} / \mathrm{L}$, the oxygen content in the concrete pore solution is thus very little. When the concrete is in the alternate wet-dry condition, the oxygen can diffuse to the rebar surface through the pores in concrete during the drying process. Then, in the wetting process, the permeation of external solution will further force the oxygen in pores toward the inner layer of concrete. It is reported that the oxygen permeability in concrete decrease with increasing water saturation degree of concrete [51]. Therefore, compared with the immersion condition, the alternating wet-dry process is more beneficial to the diffusion of oxygen to the steel surface, which can replenish the oxygen consumed by the cathodic reaction and accelerate the oxygen reduction reaction.

As the chlorides penetrate into concrete through the pore solution of concrete, the chloride ion content is also affected by the wet and dry condition of the concrete. For the solution saturated concrete, chloride ions would mainly transport by the diffusion due to concentration gradient. The chloride concentration gradually decreases with the increase in the concrete thickness, and it increases with the increase in the immersion time [52]. When the concrete is in the alternate wet-dry condition, the chloride ions also diffuse to the pores of the concrete together with the external solution during the wetting process. Then, during the drying process, the chloride concentration in the concrete pores gradually increases with the evaporation of water [53]. Therefore, the chloride concentration in the concrete pores in the wet-dry alternation condition is higher than that in the immersion condition. It is proposed that in wet-dry cycles, the chloride content was caused by not only the concentration gradients, but also the water evaporation and wetting process. Moreover, these wet-dry cycles could result in the increase in the depth of chloride ion penetration, which will cause significant acceleration of the anodic dissolution reactions [54].

The sufficient oxygen supply and high chloride concentration in tidal zone can not only accelerate the occurrence and propagation of local pitting process to form the deep pits, but also enhance the general corrosion to form the thick rust layer in the long-term corrosion. Therefore, the corrosion rate of RC sample in the tidal zone is always higher than that in the immersion zone.

\section{Conclusion}

1. The corrosion of RC samples in both the immersion and tidal zones undergoes the passivation stage, the pitting stage and the general corrosion stage. The corrosion rate of RC samples for both the immersion and tidal zones quickly increases in the pitting stage, and it gradually reaches a stable value with the transformation from pitting to general corrosion.

2. The pitting depth on local surface and the rust thickness on the overall surface of rebar in the tidal condition are always larger than those in immersion condition, which is attributed to the faster corrosion rate in tidal zone 
caused by the concentrated chloride ions and sufficient oxygen supply.

3. The long-term corrosion rate of rebar in tidal zone is two times higher than that in immersion zone.

Acknowledgements This work was financially supported by the National Natural Science Foundation of China (Nos. 51501201, 51501204 and 51671200) and the National Key Research and Development Program of China (No. 2017YFB0702302).

\section{References}

[1] A. Kashi, A.A. Ramezanianpour, F. Moodi, Constr. Build. Mater. 151, 520 (2017)

[2] U. Angst, B. Elsener, C.K. Larsen, Ø. Vennesland, Cem. Concr. Res. 39, 1122 (2009)

[3] X. Shi, N. Xie, K. Fortune, J. Gong, Constr. Build. Mater. 30, 125 (2012)

[4] D.V. Val, M.G. Stewart, Struct. Saf. 25, 343 (2003)

[5] W.J. Zhu, R. François, Q. Fang, D.L. Zhang, Cem. Concr. Compos. 71, 144 (2016)

[6] W. Morris, V.M. Vazquez, Corros. Rev. 20, 469 (2002)

[7] R.E. Melchers, C.Q. Li, Cem. Concr. Res. 39, 1068 (2009)

[8] R. Blair, B. Pesic, J. Kline, I. Ehrsam, K. Raja, Acta Metall. Sin. Engl. Lett. 30, 1 (2017)

[9] C.G. Berrocal, K. Lundgren, I. Löfgren, Cem. Concr. Res. 80, 69 (2016)

[10] YSh Ji, G.M. Zhan, ZhCh. Tan, Y.J. Hu, F.R. Gao, Constr. Build. Mater. 79, 214 (2015)

[11] I. Khan, R. François, A. Castel, Cem. Concr. Res. 56, 84 (2014)

[12] M. Safehian, A.A. Ramezanianpour, Constr. Build. Mater. 48, 287 (2013)

[13] C. Jiang, Y.F. Wu, M.J. Dai, Constr. Build. Mater. 158, 1073 (2018)

[14] M. Thomas, in Marine Concrete Structures, ed. by M.G. Alexander. 6 - The durability of concrete for marine construction: Materials and properties (Woodhead Publishing, Cambridge, UK, 2016), pp. 151-170

[15] M.H. Tadayon, M. Shekarchi, M. Tadayon, Constr. Build. Mater. 123, $611(2016)$

[16] Y.H. Gao, J.Z. Zhang, S. Zhang, Y.R. Zhang, Constr. Build. Mater. 140, 485 (2017)

[17] A.A.E. Fattah, I. Al-Duais, K. Riding, M. Thomas, Constr. Build. Mater. 165, 663 (2018)

[18] M. Otieno, H. Beushausen, M. Alexander, Cem. Concr. Res. 79, $373(2015)$

[19] C. Cao, M.M.S. Cheung, Constr. Build. Mater. 51, 75 (2014)

[20] C.Y. Gong, X.Y. He, T.W. Li, S.Z. He, X. Cheng, L.Y. Huang, Y. Zhang, J.B. Chen, S.H. Xu, J.B. Zhang, C. Zeng, Acta Metall. Sin. Engl. Lett. 30, 399 (2017)

[21] C. Fu, N. Jin, H. Ye, X. Jin, W. Dai, Corro. Sci. 117, 11 (2017)

[22] A. Guo, H. Li, X. Ba, X. Guan, H. Li, Eng. Struct. 105, 1 (2015)
[23] T. Cheewaket, C. Jaturapitakkul, W. Chalee, Constr. Build. Mater. 37, 693 (2012)

[24] S.V. Nanukuttan, P.A.M. Basheer, W.J. Mccarter, L. Tang, N. Holmes, T.M. Chrisp, G. Starrs, B. Magee, Constr. Build. Mater. 93, 831 (2015)

[25] O. Poupard, V. L'Hostis, S. Catinaud, I. Petre-Lazar, Cem. Concr. Res. 36, 504 (2006)

[26] A. Dasar, H. Hamada, Y. Sagawa, D. Yamamoto, Constr. Build. Mater. 149, 690 (2017)

[27] M. Torres-Luque, E. Bastidas-Arteaga, F. Schoefs, M. SánchezSilva, J.F. Osma, Constr. Build. Mater. 68, 68 (2014)

[28] X. Dérobert, J.F. Lataste, J.P. Balayssac, S. Laurens, NDT and E Int. 89, 19 (2017)

[29] JTJ 270-98, Testing code of concrete for port and waterway engineering, in China (1998)

[30] J. Wei, X.X. Fu, J.H. Dong, W. Ke, J. Mater. Sci. Technol. 28, 905 (2012)

[31] P.S. Mangat, M.S. Elgarf, ACI Struct. J. 96, 149 (1999)

[32] Y. Ballim, J.C. Reid, Cem. Concr. Compos. 25, 625 (2003)

[33] T.A. ElMaaddawy, K.A. Soudki, ASCE J. Mater. Civ. Eng. 15, 41 (2003)

[34] X. Mu, J. Wei, J.H. Dong, W. Ke, J. Mater. Sci. Technol. 30, 1043 (2014)

[35] ASTM G1-03, Standard Practice for Preparing, Cleaning, and Evaluating Corrosion Test Specimens, ASTM, International, West Conshohocken PA (2011)

[36] ASTM C876-91, Standard Test Method for Half-Cell Potentials of Uncoated Reinforcing Steel in Concrete, ASTM International, West Conshohocken, PA (2009)

[37] C. Liu, Q. Bi, A. Leyland, A. Matthews, Corros. Sci. 45, 1257 (2003)

[38] J. Wei, J.H. Dong, W. Ke, Br. Corros. J. 47, 31 (2012)

[39] C. Andrade, J.A. González, Werkst. Korros. 29, 515 (1978)

[40] J.A. González, C. Andrade, Br. Corros. J. 17, 21 (2013)

[41] S.G. Millard, K.R. Gowers, Js. Gill, in: Malhotra VM (eds.), American Concrete Institute SP 128, Detroit, 1991, p. 373

[42] F. Mansfeld, Electrochim. Acta 35, 1533 (1990)

[43] L. Fan, Z.Y. Liu, W.M. Guo, Acta Metall. Sin. Engl. Lett. 28, 866 (2015)

[44] J. Wei, J.H. Dong, W. Ke, Constr. Build. Mater. 25, 1243 (2011)

[45] G.K. Glass, N.R. Buenfeld, Corros. Sci. 42, 329 (2000)

[46] R.R. Hussain, Cem. Concr. Compos. 33, 154 (2011)

[47] A. Carnot, I. Frateur, A. Zanna, B. Tribollet, I. Dubouis-Brugger, P. Marcus, Corros. Sci. 45, 2513 (2003)

[48] B. Huet, V. L'Hostis, F. Miserque, H. Idrissi, Electrochim. Acta 51, $172(2005)$

[49] J. Shi, W. Sun, J. Jiang, J. Jiang, Y. Zhang, Constr. Build. Mater. 111, 805 (2016)

[50] U. Angst, B. Elsener, C.K. Larsen, Øystein Vennesland. Electrochim. Acta 56, 5877 (2011)

[51] S. Real, J.A. Bogas, Constr. Build. Mater. 137, 21 (2017)

[52] Z. Szweda, A. Zybura, Proced. Eng. 57, 1121 (2013)

[53] P. Aruz, Constr. Build. Mater. 176, 638 (2018)

[54] J. Wu, H. Li, Z. Wang, J. Liu, Constr. Build. Mater. 112, 733 (2016) 